\title{
Control in a Management System in Modern Conditions.
}

\author{
Khanif Sharifzyanovich Mullakhmetov ${ }^{1}$, Rosalia Mullamehametovna Aminova ${ }^{1} \&$ Elvir Munirovich \\ Akhmetshin $^{2}$ \\ ${ }^{1}$ Branch of Kazan Federal University in Naberezhnye Chelny, Naberezhnye Chelny, 68/19 (1/18), 335, Russian \\ Federation \\ ${ }^{2}$ Branch of Kazan Federal University in Elabuga, Elabuga, Kazanskaya Street, 89, Russian Federation \\ Correspondence: Khanif Sharifzyanovich Mullakhmetov, Branch of Kazan Federal University in Naberezhnye \\ Chelny, 423812, Naberezhnye Chelny, 68/19 (1/18), 335, Russian Federation. Tel: 79-06-333-0061. E-mail: \\ mkhsh007@gmail.com
}

Received: August 24, 2014 Accepted: September 7, 2014 Online Published: November 27, 2014

doi:10.5539/ass.v10n24p237

URL: http://dx.doi.org/10.5539/ass.v10n24p237

\begin{abstract}
To the 90's of the last century the characteristics of environment of organizations functioning and development highlighted the ability to organize the implementation of planned ideas by Management. The given trend is caused by the lack of effective management tools for planning and control, which are adequate to the modern management models, and an attempt to solve the problems of modern management by the traditional methods and mechanisms. The purpose of this work was to identify the specific characteristics of the strategic and anti-crisis management system; study of the role of control in strategic and anti-crisis management based on their characteristics; development of general approaches to the effective control formation in the strategic and anti-crisis management system. In which case, we proceeded from the basic provisions of control organization in the management system, and established theories and global practices of management. In this article we suggest a control mechanism, based both on the system and process approaches to the management organization, in which the place and role of control procedures is examined stage by stage. The process of strategic control represents a set of interacting closed circuits at the strategic and operational levels: the strategic control is based on the methods and mechanisms of control at the operational level, which provide the toolkit to control the strategic objectives implementation. In considering the crises as the destruction of existing parameters system of the organization's activities and the transition to a new state, maximum relevant to the changed characteristics of environment of organizations functioning and development, the role of control reveals, on the one hand, at the prevailing independent creative activity of personnel, and forced hard managing, on the other hand. The requirements to the control in the anti-crisis management system, based on an analysis of crises and the specificity of amid the crisis management were formed. The end result of the conducted study are the proposed models and plans control actions in the systems of strategic and anti-crisis management system, based on a systematic approach to management processes and control, which take into account the influence of external factors and the internal potential of the organization.
\end{abstract}

Keywords: management, strategic control, control in the anti-crisis management system, systematic approach, process approach

\section{Introduction}

The role of control in the management system.

By stressing the importance of control and its integratedness with other management functions the authors of the famous book "Principles of Management" M. Mescon, M. Albert and F. Khedouri write: "The control is a fundamental element of the management process. Neither the planning, the creation of organizational structures, nor motivation should not be considered entirely separately from the control. Indeed, actually all of them are the integral parts of the overall control system of this organization" (Mescon et al., 2002).

Peter Drucker has defined the correlation of terms "control" and "management" this way: "... If we express the basic idea of these terms extremely compressed, the control is the measurement and information and management-is, primarily, an action. Thus, the purpose of control is to identify what is happening and the purpose of management-is to ensure the work performed is corresponded to the initial plans, so "control" 
provides information on the basis of which the "management" is performed, i.e. taking the appropriate action" (Drucker, 2001).

As we can see, the role of control is to provide information for the management activities and information, obtained through the feedback channels, is one of the main sources, when making the managerial decisions.

The purpose of control as the subsystem of management systems is to increase the effectiveness of managerial decisions. To achieve this goal, the control solves the following tasks:

a) providing a relevance (demanded to solve the problem) and qualitative (accurate, timely and complete) information on deviations in the functioning and development of organization (on the problem) to prepare and make the managerial decisions (operational level), to plan (tactical level), to goal-setting (strategic level);

b) monitoring of the organization functioning and development processes and the timely reporting to the management on the significant deviations from the implementation standards and expected results (desired state of management subjects and processes);

c) comparison of the obtained and expected results and identification of deviations; collection, collation and analysis of deviations, their consequences and causes, providing of reasonable options of corrective actions, which are adequate to the consequence of identified deviations (what it led to, and how best to eliminate the negative consequences of deviations) and their causes (why did it become possible, and what should be done in the future to not be repeated) to the management (Mullakhmetov, 2010).

To complete the first task you shall use the preliminary control methods, the second task-the current control and the third-the final control.

Thus, the control provides information, necessary for the evaluation of certain functions and management techniques, tasks and measures, management processes in general and, eventually, the organizational effectiveness to the management.

The analysis of problems associated with the monitoring activities in the economic management system of some countries shows, that the phase of control in the managerial cycle is the most sensitive to the negative economy trends. In this case, the reaction of control is manifested in the improvement of its substantive part: methods, mechanisms, technologies and control systems (Mullakhmetov, 2008).

Taking into account its importance for the modern management it seems appropriate to examine separately the control organization in both systems-strategic and anti-crisis management. In these models, the scourge of modern management is uncertainty, which manifests itself more clearly.

The characteristics of today's business environment require managers to have the strategic thinking. The continuous changes require changes and correction of company strategy and it's an ongoing process. The manager must know the strategic position of the company, be able to allocate the main factors and nature of their impact on the company, and correctly detect the moment of change in strategy (Thompson \& Strickland, 2002). The estimation of activity, detection of changes in the environment of company functioning and making of timely and appropriate to the changes corrections is impossible without an effective control system.

Sooner or later, an inadequate response to the changes in the environment by the management leads to a crisis of the company. The experts believe that actions of management shall be both active and adaptive (Pearce \& Robinson, 2013), (Thompson \& Strickland, 2002), (Campbell \& Lachs, 2004). In our opinion, such approach is dictated by the ambiguous role of crises: on the one hand, it is the destruction of the existing order, on the other-a transition (or the ability to transit) to a new state, harmonized with the existing environment (Kochetkova, 2012). Accordingly, the control system in times of crisis should be built by taking into account the given circumstances.

\section{Materials and Methods}

The strategic control organization.

The essence of strategic control in addition to emphasizing the controlled object (organization, region, etc.) and the controlled subject (implementation of the strategy) involves substantial changes of the entire control process. These changes are determined by the specific characteristics of the strategy as a target function of management.

In our opinion, the main characteristics of the strategy that need to be considered first and foremost during the establishment of a system of strategic control are the following:

a) special meaning and critical importance of the strategy to for its successful functioning and development of the organization in the long term, to ensure its competitiveness;

b) a long period of planning (generally, 5 to 10 years). 
In modern complex (presence of a variety of factors of internal and external environment, directly or indirectly affecting the activities of the organization) and dynamic (with rapid and interrelated changes of factors) medium of functioning and development of the organization the strategic goal setting for a long period creates a high level of uncertainty that shall be minimized taking into account a special role of the strategy in the life-sustaining activities of the organization. Accordingly, the strategic control system shall be established with due regard for these circumstances. Furthermore, at the operating level it is necessary to change the scope, methods and mechanisms of control.

We regard the process of management control as the log-repeated recurring stages, as shown in Figure 1:

1) Identification of the desired state of the controlled object (the desired state of an object is defined during the planning process; the definition of the desired state is the prerogative of the planning function, but not of control; at the initial stage of control, we identify the desired state of the object, the parameters defining the desired state, the standards according to the indications and maximum allowable deviations from the standards);

2) Identification of the actual state of the controlled by conducting the necessary and possible control procedures;

3) Comparison (opposition) of the actual and desired states of the controlled object according to the specified parameters, detection of the deviations;

4) Collection, compilation, analysis and evaluation of deviations;

5) Corrective actions adequate to the specified deviations, their consequences and causes; in this case the corrective actions can be directed to the management decisions and their implementation, and the changes in the organization's objectives (Mullakhmetov, 2011).

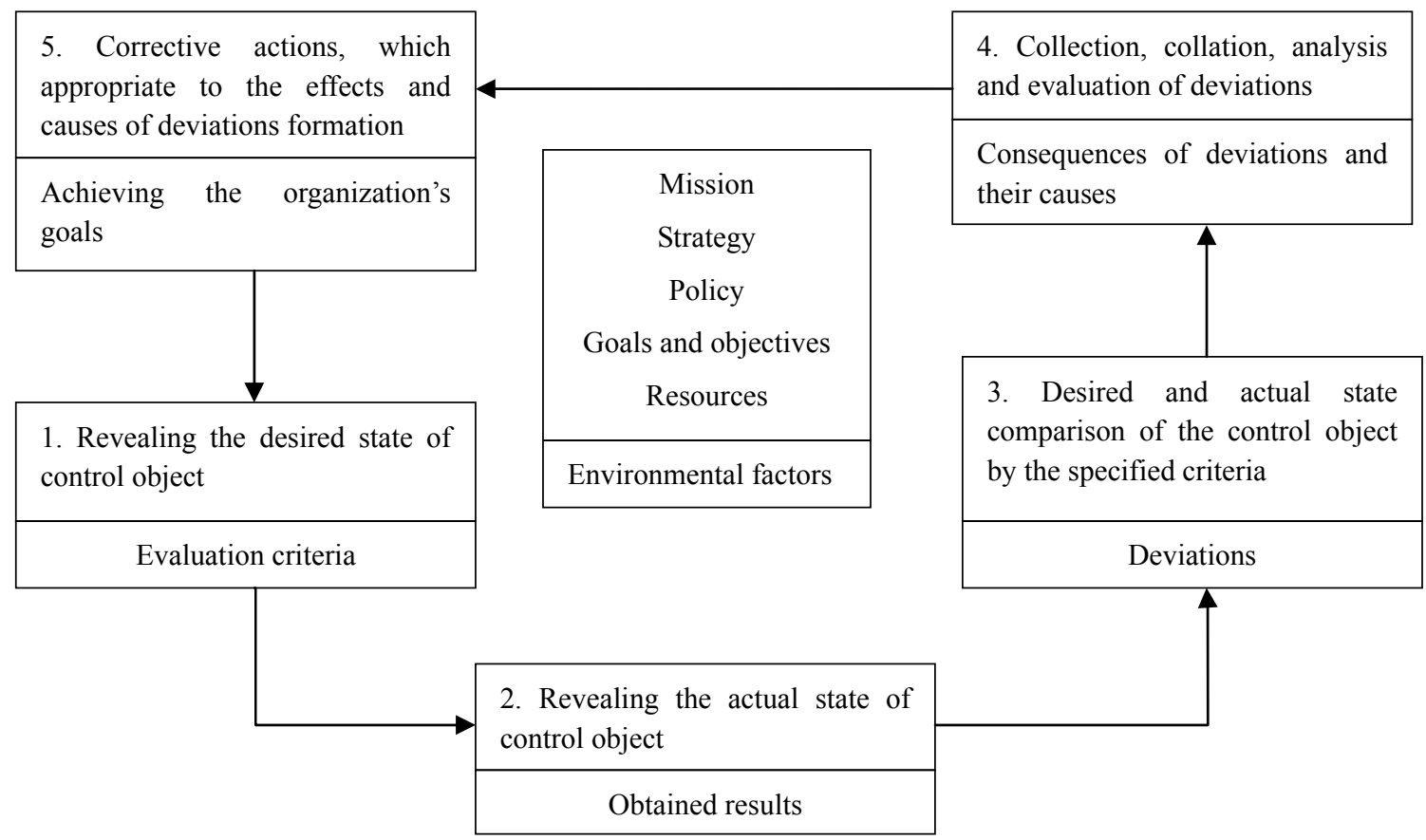

Figure 1. Control process flow diagram

In our view, the strategic control process in accordance with the strategy characteristics, which acts as the objective function of Management, is expedient to build by the following stages.

1) Identification of the major characteristics of the strategy that depending on the strategic objectives may be the major markets, market shares, sales volume, efficiency of the activity, diversification of activities, the target needs of the customers, the preferred strategic alliances, etc. In this case it is critically important to identify the preconditions (assumptions and predictions) on which the strategy is based. The prerequisites for strategic planning are primarily environmental factors (inflation, the policy of state regulation, the demand and supply of financial resources, technologies, demographic and social processes, and other facts that have an indirect impact on the organization) and the industry environment factors (the customers, suppliers, competitors, creditors, trade unions, consumer associations and other facts that have a direct impact on the organization). 
Upon control over the implementation of the strategy it is necessary to constantly refine the strategic assumptions that are to systematically check the assumptions on which the strategy is based with respect to their relevance.

2) Strategic foresight. Since the strategic prerequisites reflect the characteristics of a specific area related to the activities of the organization or having been in direct connection with the activities of the organization, there is a risk of omission of factors that are not directly related to the organization and its activities, but in the future could have a significant impact on the organization and its strategy. The object of the strategic foresight is to monitor the events occurring in the external and internal environment of the organization in order to assess their possible impact on the strategy (Mullakhmetov, 2013).

3) Strategy implementation control. This stage is carried out through a number of mechanisms.

a) The response to the special circumstances that are usually identified by the results of the first two phases: clarification of the strategic assumptions or the strategic foresight. Effective and rapid response to unforeseen circumstances allows to adapt the strategy of the organization to the new conditions, to keep the confidence of the staff in their actions and their loyalty to the management system. In addition, the actions of the management adequate in respect of the occurring changes keep the staff confident with a sense of control over the situation, making their work psychologically comfortable.

b) Control over the task accomplishment pursues the aim of assessing the need for changing the strategy according to the results of the intermediate stages of the strategy implementation.

The tasks to be controlled are usually divided into two types: the organizational results achieved at the intermediate stages of the general long-term strategy and the results of the strategic projects.

Monitoring of the strategic projects allows managers to estimate the overall strategy: whether the organization is developing in accordance with the intended purposes or the strategy needs to be adjusted.

In this respect, the strategic projects are the certain indicators that allow us to correctly assess the success of the implementation of the strategy, for example, in the case of a more detailed development of the individual projects at the planning stage with the determination of efficiency and effectiveness, and their expected values, as well as the impact of the indicators on the success of the overall strategy. This approach allows to organize the systematic control over the project according to the established parameters and to provide a reasonable assessment of the success of the implementation of the strategy as a whole (Mullakhmetov, 2013).

The control over the intermediate results is carried out at the control points that can be used for determination of the implementation of the strategy. Typically these points are the time intervals, the major investments of resources or certain events. Upon completion of the control intermediate stage the system analysis of the strategy is carried out and according to its results, the decision is made about its future: to continue the implementation of the adopted strategy, or to adjust it.

In additions, each of the control mechanisms of the strategy implementation involves the following steps (procedures) at the operational level:

a) decomposition of the strategic objectives to the specific controlled indicators, reflecting the progress of the strategy (it is implemented during the operational planning by drafting the action plans, work schedules, budgets, success factors, etc., and during the operation control the controlled indicators, standards and maximum permissible deviations are identified);

b) identification of the actual state of the implementation of the strategy on the basis of the established indicators;

c) comparison (opposition) of the actual state of the implementation of the strategy with the strategic goals and objectives according to the controlled parameters (the result of the stage is the information relating to the deviations);

d) collection, compilation, analysis and evaluation of deviations from the strategic goals and objectives (the result is the information relating to the consequences of deviations and their causes).

According to the analysis it is necessary to determine the causes of the deviations (internal or external factors) and their consequences (significant risks of failure of the strategic objectives or non-essential within the adopted strategy). In the case of each combination of the "cause-effect" factors (internal essential, internal non-essential and external essential, external non-essential) the appropriate corrective actions are required. For example, upon availability of the critical impact of the external factors it requires primarily to refine the strategic assumptions and higher defocusing of the strategic foresight mechanisms, since the significant deviations due to the impact of 
external factors are most likely the result of the unforeseen circumstances.

4) The corrective managerial influence, adequate deviations, their consequences and causes.

\section{Control in the Anti-crisis Management System}

The organizations of any forms of ownership (including state and local government), type of activity and sizes are subject to crisis developments. The problem of the management of organizations under the conditions of crisis for modern Russia, due to a number of objective and subjective reasons, is highly relevant, and the management and owners are clearly faced with the aim to ensure the sustainable operation and development of the organizations in the long period in the presence of recurring crises.

Many organizations, and above all the organizations with the Soviet history, attempt to solve the problem of management in the presence of a systemic crisis by means of strict administration and control. The practice shows that this approach aimed at preventing the crisis, is doomed to failure and, at best, provides some slowing of the crisis developments.

Very often the manifestation of the crises is regarded as a systematic failure by the state financial institutions and organizations to fulfill their obligations. Such a narrow interpretation can be contrasted with the consideration of crisis as a turning point, the transition to a new qualitative state, i.e. the new opportunities. Crisis in some sources is considered as "...the extreme intensification of the internal production and socio-economic relations in the internal environment of the organization, as well as relations with the external environment; the state of destruction of the existing system and parameters of its activities" (Kochetkova, 2012).

The crises are an objective phenomenon in the socio-economic systems-from the standpoint of the management they represent a situation in which the subsystem of the organization management is not able to ensure the implementation of its objectives. The crisis is characterized by a set of interrelated situations in the internal and external environment of the organization, increasing the comprehensiveness, the rate of changes of factors, uncertainty and ultimately the risk of making the administrative decisions by the managements, inadequate situations.

The practice and theory of management have developed two main approaches to the crises. The first approach suggests that the crises are objectively inherent by any socio-economic processes and, accordingly, the crises are inevitable in any business, but there is a rigorous approach to the technique of modeling the internal environment of the organization that allows overcoming the crisis ("German theory"). The second approach suggests that a systemic crisis can be avoided through the preventive measures. This opinion is also widespread in Russia (Kochetkova, 2012).

The existence of any organization as a system can be considered as the alternating processes of regulation of the parameters of its activity (order), and destruction of the former parameterization in order to form a new one (chaos) (Kochetkova, 2012). Since the actual states of the objects (sub-systems and elements of the organization as a system) and processes (relations between the elements and subsystems) in practice rarely coincide with the planned parameters (with the desired state), the chaos is potentially organically inherent environment of operation and development of the organization. The only question is what kinds of deviations from the planned parameters shall be considered valid, i.e. not disturbing the established system of the parameters, and what kinds shall be not. The local and temporary violations of the order (chaos and, respectively, anti-recessionary or fractal management) are the inevitable consequences of the functioning of the organizations in the market conditions. Since the state of the organization orderliness determines the type of management, the natural critical necessity for the effective operation of the organizations in the long terms is becoming the system tracking (control) of the parameters of its objects and processes (Mullakhmetov, 2013).

The risk of the crisis in organizations is always available, so it is necessary to conduct the constant control in order to predict, recognize and prevent the crisis situations. In this case it is necessary to monitor not only quantitative but also qualitative indicators reflecting the trends of changes in the organization. An effective control system should develop the methods, tools and technologies of recognition of the organization entering as a whole and its subsystems into the state of systemic crisis; we shall be able to diagnose the moments of transition and the maximum development of the crisis.

As for the relation to the control activity the dialectical pair "order-chaos" can be transformed as the "predictability-flexibility" of the staff behavior. The challenge is to find a balance between the desire to improve the predictability of the activities of employees and the desire to develop their initiative and creative attitude to the work, as well as the ability to quickly and adequately respond to the changes and transformations (to the conditions of chaos). If the first fact means strengthening the administration and control, control over the 
personnel actions, so the second fact requires a nominal control procedures and performance control.

Thus, in the case of the systemic crises in the organization of the control activities there are two opposing trends. On the one part, the need to adapt to the crisis developments requires an increase in the independent creative activity of the personnel that establishes the opportunities for the transition to a dissipative structure and a self-sustaining organization. In this case the amount of control procedures is significantly reduced, they are becoming milder, aiming at the performance evaluation, the micromanagement of the staff is excluded, and the methods of self-control are developing. One of the major factors in the success of this approach is the appropriate corporate culture, the presence of a system of mutual claims on the horizontal (coordinating) bonds. On the other part, the crisis requires maximum concentration of efforts, centralization of the resources, elimination of the unproductive losses, restructuring of the management while reducing the administrative apparatus. Such actions can be successful in case of the amplification of centralization in the control system, rigid control procedures, prompt and adequate evaluation of the deviations, i.e. the control strengthening (Mullakhmetov, 2013).

These trends reflect the two sides of the crisis: the first one is that the crisis is as a transition to the new state of the organization; and the system of management and control as its subsystem are focused on the development, use the creative component of the crisis; the second one is that the crisis is as the destruction of the previous system of the parameters of the organization activity, and the system of management and control are aimed primarily at preserving the previous state of the organization.

Naturally, saving resources and using them in order to maintain the main processes in the organization also contribute to the survival of the organization in times of crisis, but the transition to the new state, the development of the organization cannot be solved only by the methods of strict administration and control. It shall be kept in mind that rigid formalization of the systems and processes (strict administration and control) does not allow them to develop, thereby depriving them of adaptability and gradually leading to the destruction (the crisis).

According to one of the basic principles of the organization of the control activity-the principle of assessment based on the results-the objects and processes are checked both as to compliance with the applicable laws, management policies, and operational management decisions (internal regulatory framework), i.e. as to the form, and as to the results achieved, i.e. as to the merits; thus, the defining criterion for evaluating is the results obtained as to the achievement of the goals of the management system. The principle of assessment on the results promotes the continuous improvement of the internal regulatory framework on the basis of the results obtained, and while changing the management solutions it provides the adaptability of the organization (its systems and processes) to the new conditions.

\section{Results}

Based on the above the strategic control process can be represented as two interacting circuits (Figure 2).

At the strategic level the circuit consists of the following stages:

1) Strategy identification; the result-identification of strategic prerequisites and basic strategy characteristics;

2) Strategic foresight; the result-identification of events that could potentially have an impact on the strategy;

3) Implementation strategy control that is carried out by the interim results, by the results of strategic projects implementation by reacting on the basis of circumstances; the result-evaluation of strategy implementation success;

4) Corrective managerial impacts that are adequate to revealed deviations, their consequences and root causes; the result-achievement of strategic goals and objectives of the organization.

At the operational level the circuit ensures the implementation of strategy control through the response mechanisms to the particular circumstances, as well the implementation of tasks performance control (the intermediate results control and the strategic projects monitoring). All of those mechanisms, which are the toolkit of the third stage at the strategic level-Strategy implementation control, are impossible without performing the following stages: identification of controllable indicators, their standards and maximum permissible deviations; identification of the actual state of the strategy implementation progress; comparison of the actual and the desired states of the strategy implementation progress at time of verification; collection, collation, analysis and evaluation of deviations.

At the operational level the circuit is also completed by the corrective management impacts that are designed to achieve the interim results, controllable indicators of strategic projects and specific tasks. Based on the analysis 
and evaluation of deviations the decision on correction strategy can be adopted. Thus, the interaction of control circuits at the operational and strategic levels occurs during the development of corrective managerial impacts: the achievement of controlled indicators at the operational level shall ensure the achievement of goals and objectives at the strategic level.

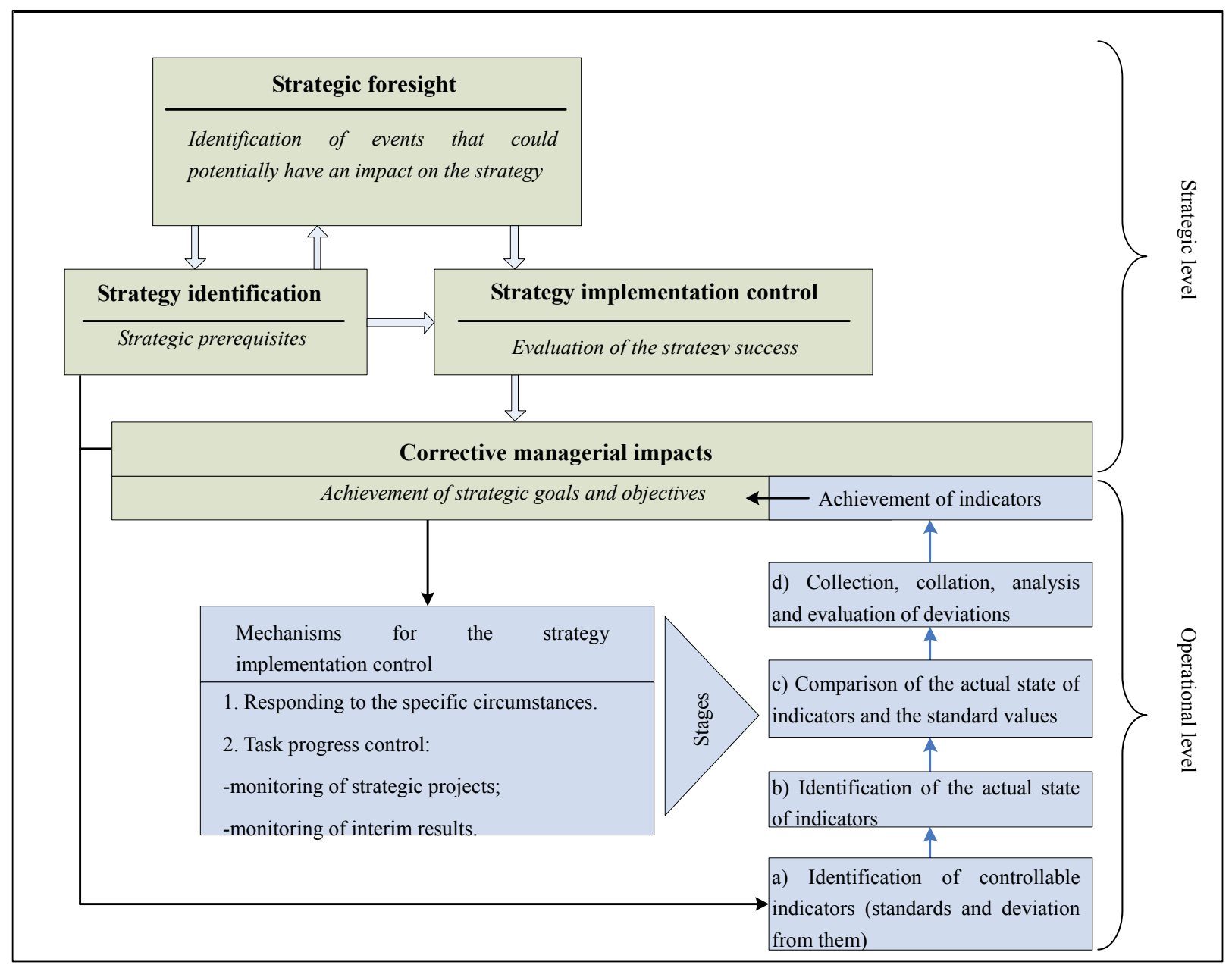

Figure 2. The proposed scheme of strategic process control

Based on the above, we can make some generalizations and conclusions.

Strategic control consists of operational and strategic levels; at the same time the operational level provides a toolkit to implement the strategic level: it's impossible to carry out the strategic control without mechanisms, methods and procedures of operational control.

Strategic control is a combination of all three types of control: preliminary, current and final. At the strategic level, the preliminary (pre-emptive) control is the predominant, which assuming a constant systematic analysis of the external environment at the stages of strategy identification and strategic foresight; at the operational level the subsequent (final) control of completed stages, projects and specific tasks is predominant; at both levels the current control of the strategy process implementation is carried out.

At the strategic level the control, while maintaining its essential characteristics, is modified in order to effectively monitor the specific characteristics of the control subject-strategy process implementation.

During the strategic control the role of control enhances essentially-the strategic plans, which fail to ensure the achievement of strategic goals, are subject to the operational correction on the results of actualization of strategic prerequisites and strategic foresight. The role of analytical procedures increases-they permeate the whole process of strategic control, starting from the analysis of environmental factors functioning and the organization development and ending the impact analysis and evaluation of the corrective managerial influences to achieve 
the strategic objectives.

The essential changes in the environment of organization functioning and development are increasingly becoming a cause of failure to reach the strategic goals. The systematic approach to organizing the strategic control is required. The need for continuous actualization of strategic prerequisites, mainly by the environmental factors and the observation of events, occurring within the organization and the external environment in order to find the unexpected information, inherent in the strategic control, uniquely allocate the organization as an open system.

For the efficient organization of strategic control the traditional control system is gradually transformed into the controlling system, aimed to provide the information support of strategic management system, which considers first of all the essential changes in the environment of organization functioning and development for the period of strategy development and implementation as a reason for failing to achieve the organization's goals.

The consideration of organization as an open system experiencing an intensive exposure to environmental factors-firstly, and a long period of planning, which creates a high level of uncertainty-secondly, and the critical importance of strategy to ensure the competitiveness of organizations in the long term require high skill level of controllers in the strategic control. The controllers should not only identify the deviations, but first and foremost to determine the consequences of deviations and their causes and suggest the adequate to them variants of corrective managerial influences.

The analysis of anti-crisis management practice shows that the entire methodological base (organization principles, requirements for the efficient system of control, etc.) and the toolkit of control activities in the anti-crisis management system work effectively. At the same time, the significance of requirements is amplified in the following directions:

a) predominantly the preliminary control, especially in the financial activities of the organizations, and the control amplification in the financial management system, they both can detect a crisis in the very early stages of development;

b) risk-oriented approach to organizing the control activities: measures on the revealed deviations should be adequate to risks of failing to achieve the organization's goals, both necessary and sufficient to prevent the bankruptcy; such approach ensures the compliance with the economic control principle;

c) compliance with the precautionary principle in the analysis and evaluation of deviations identified by the control system (excessive optimism is not appropriate);

d) the timeliness of control procedures and your attitude to the repetitive essential deviations as to the possible signs of upcoming crisis;

e) Information on the results of control activities should be structured and formalized so that you can provide the swift and decisive actions of management into the system and essential deviations of indicators for the organizational performance (Mullakhmetov, 2013).

For the constructive development in times of crisis the modern Management is based on the full potential, accumulated by the management theory and practice. The control as a management subsystem and in accordance with the requirements for the effective control system (first of all: flexibility, warning of possible deviations and reasons of their occurrence, risk-oriented approach, continuous improvement) in the anti-crisis management system shall contribute to the progressive organizational development and concentrate on the creative part of control activities, as a dissemination of best practices and learning effect. Business Management shall be deprived of illusions about the crisis, understand and accept the crisis as an objective phenomenon in the social and economic system and in the business, develop and maintain an anti-crisis program of the organization, be able to recognize the onset of the crisis and be ready to implement the anti-crisis measures. At that the control, as a major function of management, which has an integration nature, plays a critical role.

\section{Discussion}

Today, the researchers of the control problem allocate a revolutionary change in the business environment functioning as a factor that determines the development of management. Richard L. Daft writes: "In light of dramatic events at the beginning of the XXI century the main theme of management is the spread of tumultuous changes and their impact on the organization" (Daft, 2009). The author characterizes the current business environment as "an economic mess, political confusion, and overall uncertainty" and believes that for the successful management it is necessary "to go beyond the techniques and ideas, traditionally taught in the management courses". By noting the need for changes in the new conditions and the control subsystem R.L. Daft 
writes, that it is necessary to focus on the development and not on the control, and only the adaptation to the rapid changes in the situation will lead to the overall corporate effectiveness. Along with that, the author points the need to preserve the best traditions of management thinking (Daft, 2009). As we can see, in a dialectical pair "order-creativity" the emphasis should be shifted towards the latter.

Highlighting the environmental factors influence significance on the control subsystem J. Pearce and R. Robinson write that "... the accelerating themes of changes in the global market have turned the strategy modernization into the independent strategic control problem for many organizations". In this the strategic control is considered by the authors in the traditional manner as the analysis of strategy process implementation, detection of problems and changes in circumstances and making the necessary corrections (Pearce \& Robinson, 2013).

In our opinion, the rethinking the role of control in the strategic management system took place at the end of XX-the beginning of XXI centuries: financial results without the constant systemic monitoring of intangible results in operational activities of the organization and the development of human resources cannot grow constantly and sustainably. Despite the difficulties of defining and measuring, you need to set and control the quantitative indicators for each of those directions, which reflect the essence of their main processes and contribute to the strategy implementation (Mullakhmetov, 2013).

The most relevant mechanism of strategic control, based on the balanced scorecard, is a balanced strategy map, offered by Robert Kaplan and David Norton (Olve et al., 2005). The balanced strategy map is an effective way of interaction between the mechanisms of operational strategic control. Inherently it is the result of applying the concept of management by objectives of Peter Drucker in the strategic management and represents the objectives tree. The value of a balanced strategy map in terms of control organization in the management system of modern companies is also in the following aspects: firstly, thanks to correct interlink ages of financial results with the efficiency of management the maps allow you to give a reasonable assessment of managers' activities and thereby reduce the level of agency conflicts with the corporate management system; secondly, the scorecards reflect and documented fix the transfer of strategic goals and objectives into performance indicators, form a highly interconnected and balanced responsibilities of Managers throughout the hierarchy of management, which makes it possible to provide the system control of management activities (Mullakhmetov, 2013).

According to the authoritative international experts, over the coming years the global economic recovery cannot be expected (Khitalsky, 2012), therefore the relevance of anti-crisis management increases in the modern economy. Moreover, it's not only due to the global economic crisis, but also to the objectively inherent life cycle stages of social and economic systems.

Along with that, the opinions of theorists and practitioners about the essence of such management are different. One of them believe that the main purpose of anti-crisis management is the crisis state prevention (Barinov, 2002), and others consider it as the management aimed directly to the company bailout (Koshkin, 2000). Still others reduce the essence of anti-crisis management only to the financial mechanisms (Kryzhanovsky et al., 1998), and some of them consider the management of social and economic systems within the bankruptcy procedures, and, in particular, during the liquidation procedure, when the whole activity is directed on the company liquidation. But more often there is an opinion that the anti-crisis measures should be taken, when the enterprise financial position is already becoming unsatisfactory, and the prospect of bankruptcy is real.

We believe that the use of systematic approach is expedient, when the anti-crisis management is considered as a set of measures starting from the crises forecasting to overcoming, and the use of crises consequences for the further development, as any crisis has the potential for development and its main function is in disposal of non-viable system elements.

\section{Conclusion}

The general tendency of the management and control evolution shows that the management a whole and the control as a subsystem of management system are becoming more "democratic": the volume of managerial influences and control procedures is reduced, their content becomes softer, and the role of self-control increases. The philosophy of control changes from the centralized and strictly formalized procedures to the decentralized control by results; the creative role of control as the spread of positive experience and learning effect increases. In the classic dilemma of control, consist in founding of balance between the order and flexibility, the emphasis is placed toward the latter; in the management activity the characteristics of initiative and creativity come to the forefront compared to the executive and order.

Those changes allow you to use the social, moral and psychological, ethical toolkit, and the culture of 
organization in the management activities, thereby increasing the effectiveness of management activities and creating the more comfortable working conditions for the personnel (Mullakhmetov, 2013).

Along with that, the control activity changes in the following directions:

- simultaneously, with decrease in the volume of control procedures, they become more complex in the substantive aspects;

- the criteria for evaluating the management activities by the results of control procedures become more complicated, they take into account the whole range of factors of internal and external environment, the factors combinations and the nature of their interactions; to the effective control organization those circumstances require a closer connection (integration) between the control and other management functions;

- complication of organizations management, predominantly due to the influence of environmental factors, determined the success of the system approach in the management, and the need to take into account the mutual influence and interrelations of the organization's subsystems in conjunction with the environmental factors gave the impetus to the development of controlling as a large corporations management tool;

- changes in the internal environment of the organization (diversification, scaling, complication of technological and managerial processes, etc.) require to create a structured system of internal control, which is adequacy of existing management system, that may become the basis for the creation of a risk management system in the organization (Mullakhmetov, 2013).

The given group of changes requires the entire arsenal of the modern methodological and instrumental support of management and control activities, has high requirements for the management personnel qualification.

Today, the traditional management, assuming the efforts to ensure the activities of the organization in a rigidly specified parameters of their activities, is no longer provide the goals achievement, since the specified parameters, in the virtue of continuous changes of environmental factors, don't match the behavior model of management system that ensures the effective management.

Within this article we don't consider the problem of corporate management and control at the present stage of the social and economic relations development, which is highly relevant according to the attention of theorists and practitioners of management to these problems (Gureev, 2006; Dementieva, 2009; Safiullin et al., 2003; Mullakhmetov, 2008).

We proceeded from the basic provisions of modern management, which ambiguously identify a range of categories and terms in the management science. The problem of measurements in the social and economic objects management (quantitative assessment of management effectiveness), the problem of correlation between the management science and other sciences (Marshev, 2005) still remain relevant. In our opinion, a rapidly changing environment of modern business, excluding the traditional management, exacerbates the problem of correlation between the art and scientific character in management.

\section{References}

Barinov, V. (2002). Crisis management: Education guidance. Moscow: FBK-press.

Campbell, A., \& Lachs, C. S. (2004). Strategic sinergizm. St. Petersburg: Piter. (Original work published 2).

Daft, R. L. (2009). Management (4th ed.). St. Petersburg: Piter. (Original work published 8).

Dementieva, A. (2009). The highest level of management in stock companies: Domestic and foreign experience. Moscow: Master.

Drucker, P. (2001). Practice management. Moscow: Williams publishing house.

Gureev, S. (2006). Myths of economy: Delusions and stereotypes which extend mass media and politicians. Moscow: Alpina Business Books.

Khitalsky, O. (2012). In a zone of controlled risks. Effective Crisis Management magazine, 5(74), (JSC Publishing house Real economy). Retrieved August 13, 2014, from http://www.e-c-m.ru/magazine/74/

Kochetkova, A. (2012). Bases of management in the conditions of chaos (uncertainty). Moscow: Read-Groups.

Koshkin, V. (2000). Crisis management: 17-modular program for managers "Management of development of the organization". Module 11. Moscow: Infra-M.

Kryzhanovsky, V., Lapenkov, V., \& Luther, W. (1998). Crisis management: The education guidance for technical colleges. Moscow: PRIOR publishing house. 
Marshev, V. (2005). History of administrative thought: Textbook. Moscow: INFRA-A.

Mescon, M. H., Albert, M., \& Khedouri, F. (2002). Principles of Management. Moscow: Delo.

Mullakhmetov, K. (2008). Corporate control. Kazan: Publishing house of the Kazan state university.

Mullakhmetov, K. (2010). Control with system of the social and economic relations. Controling, 3, 14-19.

Mullakhmetov, K. (2011). Process approach to the organization of control at the Russian enterprises. Managerial economics. Russian scientific magazine, 8, 53-57.

Mullakhmetov, K. (2013a). Control-management. Moscow: JSC Ekonomika Publishing House.

Mullakhmetov, K. (2013b). Economy and management. Russian scientific magazine. Process of the organization of strategic control for successful functioning and development organization, 7, 50-55.

Mullakhmetov, K. (2013c). Influence of development of management, culture and philosophy of the organization on control evolutions. Economic science in various cultural contexts, 1(Charlies University in Parige), 37-66.

Mullakhmetov, K. (2013d). Influence of evolution of management on the organization of control. 4th International scientific conference "European Applied Sciences: Modern approaches in scientific researches": Pages of the 4th International scientific conference, 2(Studgard, Germany), 176-182.

Olve, N., Petr, C., Roy, J., \& Roy, S. (2005). Making Scorecards Actionable Balancing Strategy and Control. St. Petersburg: Piter.

Pearce, J., \& Robinson, R. (2013). Strategic management. St. Petersburg: Piter. (Original work published 12).

Safiullin, M., Kulik, E., \& Guryanova, E. (2003). Corporate management. Kazan: KGU of V. I. Ulyanov-Lenin.

Thompson, A. A., \& Strickland, A. J. (2002). Strategic Management: Concepts and Cases. Moscow: Williams publishing house. (Original work published 12).

\section{Copyrights}

Copyright for this article is retained by the author(s), with first publication rights granted to the journal.

This is an open-access article distributed under the terms and conditions of the Creative Commons Attribution license (http://creativecommons.org/licenses/by/3.0/). 